\title{
Моделирование особенностей эпитаксиального формирования 2D- и 3D-островков c учетом изменения физических параметров двумерных пленок с толщиной
}

\author{
К.А. Лозовой, В.В. Дирко, А.П. Коханенко, А.В. Войцеховский \\ Томский государственный университет, Томск, \\ 634050, Ленина, 36 \\ тел:+7 (382) 241-3517, факс:+7 (382) 241-2772, эл. почта: lka@ sibmail.com
}

DOI 10.34077/RCSP2021-64

Гетероструктуры с двумерными слоями и квантовыми точками получили широкое применение в наноэлектронике и нанофотонике для создания фотодетекторов, солнечных элементов и светоизлучающих устройств $[1,2]$. Активно развиваются и новые направления использования таких структур: например, для создания микротекстурированных поверхностей, антиотражающих покрытий, фотонных кристаллов и микрорезонаторов [3, 4], спиновых кубитов [5]. Особое внимание в последнее время привлекается к таким перспективным 2D-кристаллам как графен и его аналоги [6]. Основным методом создания наноструктур с двумерными слоями и квантовыми точками является молекулярнолучевая эпитаксия $[7,8]$.

В данной работе рассматривается эпитаксиальное выращивание напряженных двумерных слоев германия и твердого раствора германия-кремния различного состава, а также особенности формирования квантовых точек в этих системах. Проводится теоретическое рассмотрение влияния зависимости поверхностных энергий и упругих напряжений от толщины осажденного материала на формирование двумерных слоев и квантовых точек по механизму Странского-Крастанова. Помимо этого, произведено моделирование миграции адатомов и формирования островков методом молекулярной динамики.

Рассматриваются различные стадии формирования двумерного слоя толщиной от одного до нескольких монослоев, а также появления двумерных и трехмерных островков. Особое внимание уделяется установлению возможностей преодоления нуклеации островков и предотвращения нежелательного перехода от двумерного к трехмерному росту при выращивании 2D-материалов.

Результаты расчетов подкрепляются результатами экспериментов по синтезу указанных структур на установке молекулярно-лучевой эпитаксии. В качестве модельной системы для проведения экспериментальных исследований и теоретических расчетов используется зарождение и рост двумерных слоев и квантовых точек германия и твердого раствора германия-кремния на поверхности кремния с кристаллографической ориентацией (100).

В результате получены зависимости параметра $N$, определяющего сверхструктурную перестройку поверхности, и поверхностных энергий двумерного слоя от эффективной толщины осажденного материала в широких диапазонах температур и составов. На основе полученных зависимостей от толщины поверхностных энергий и рассогласования по параметру решетки между осаждаемым материалом и подложкой строится кинетическая модель для расчета параметров формируемых двумерных слоев и островков. Результаты работы непосредственно применимы для определения условий синтеза высококачественных 2D-кристаллов и наногетероструктур с квантовыми точками, а также создания на их основе новых приборов с необходимыми характеристиками для наноэлектроники и нанофотоники.

Результаты были получены в рамках выполнения государственного задания Минобрнауки России, проект № 0721-2020-0038.

\section{Лumepamypa}

[1] Izhnin I. I., Lozovoy K. A., Kokhanenko A. P., et al. // Applied Nanoscience. 2021. https://doi.org/10.1007/s13204-021-01667-0

[2] Hendrickx N. W., Franke D. P., Sammak A., et al. // Nature Communications. 2018. V. 9. P. 2835.

[3] Ota Y., Yurasov D., Novikov A., et al. // Japanese Journal of Applied Physics. 2019. V. 58. P. 045505 (1-6).

[4] Rutckaia V., Heyroth F., Novikov A., et al. // Nano Letters. 2017. V. 17. P. 6886-6892.

[5] Hendrickx N. W., Lawrie W. I. L., Russ M., et al. // Nature. 2021. V. 591. P. 580.

[6] Yuhara J., Le Lay G. // Japanese Journal of Applied Physics. 2020. V. 59. P. SN0801.

[7] Izhnin I. I., Kurbanov K. R., Lozovoy K. A., et al. // Applied Nanoscience. 2020. V. 10. P. 4375-4383.

[8] Timofeev V., Nikiforov A., Yakimov A., et al. // Semiconductor Science and Technology. 2019. V. 34. P. 014001. 